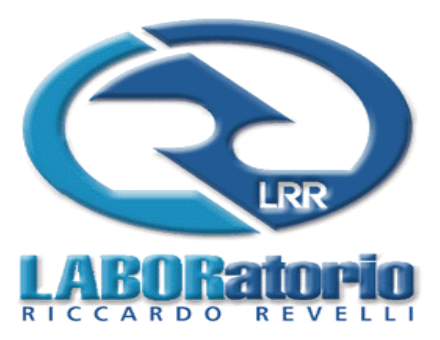

LABORatorio R. Revelli

Centre for Employment Studies

\title{
Employability of older workers in Italy and Europe+
}

\author{
Roberto Leombruni, LABORatorio Revelli, Torino \\ Claudia Villosio, R\&P and LABORatorio Revelli, Torino
}

November 2005

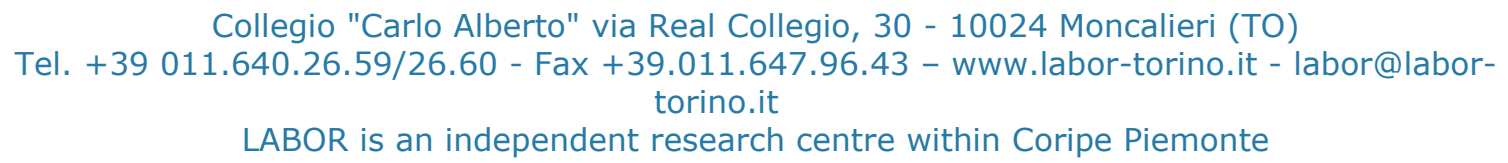

LABOR is an independent research centre within Coripe Piemonte

\footnotetext{
${ }^{\dagger}$ Paper presented at the conference "Quality in Labour Market Transitions: A European Challenge" 25-26 November 2004 Amsterdam, now under revision for publishing in W. Herremans, N. Heuvel, C. Ehrel (eds.), Active ageing: early retirement and employabilty, Steunpunt WAV - Resource Centre for Labour Market Research, Belgium
} 


\begin{abstract}
In many European countries the participation rates of older workers are worryingly low, and Italy within this picture - has one of the worst records, particularly for females. In this paper we investigate whether this signals an issue about their employability. Indeed, the non-participation of an individual does not point to an employability issue as long as it is a free choice of the person, and as long as it does not hinder their future participation in the labour market.

To address this point we single out which are the empirically most relevant factors in shaping cross country differentials. Two selection processes emerged as having a most prominent role: the life cycle decision for women of not participating to the labour market, and the access for men and women to early retirement schemes. Controlling for these selection processes international differences reduce significantly.

In both cases the main issue is the possibility that a participation choice made in a given point in time - for instance the early retirement decision - can have long lasting consequences, hindering future transition possibilities of the individuals. The magnitude of the two selection processes suggests already some policy conclusions, which are derived in the paper, and points to the need of further research to ascertain whether there are barriers to late entries and re-entries in the labour market.
\end{abstract}

Keywords: Employability; Ageing; Participation rate.

JEL codes: J14; J21. 


\section{Introduction}

The International Labour Organization (ILO) has identified the employability of the individuals as one of the key targets that policy makers have to follow in order to enhance labour markets' performance. In the ILO definition, employability is a broad concept that "encompasses the skills, knowledge and competencies that enhance a worker's ability to secure and retain a job, progress at work and cope with change, secure another job if she/he so wishes or has been laid off, and enter more easily into the labour market at different periods of the life cycle" (ILO 2000).

One of the most critical areas in European Community's labour market performance has to do with the participation rates of older workers (over 55), which in many member countries are worringly low, far below the Stockholm target of 50\%. Within this picture Italy has one of the worst records, particularly for females. The aim of this paper is investigate whether the very low participation rates of the elderly in Italy signals an issue about their employability, or rather it can be explained taking into account different national contexts.

In general, we can say that the non-participation of an individual does not point to an employability issue as long as it is a choice of the person. There are many factors that may justify low participation behaviours, and the cross-country differences may not rise any policy concern. As an example, think of the differences in family structures and in the importance of family networks. The higher the household size and/or the number of children in the family where the person is currently living, the higher the probability that s/he voluntary decides to participate in child and family care, and not in the labour market. The same situation would rise a policy concern in case the individual - once the need for family care is over - would like to come back to the labour market but there are barriers hindering re-entries.

It is important to stress from the outset that a compelling answer to this issues is out of our intentions and scope. There are many characteristics of the individuals, of their working careers, of the labour demand and of the cultural and institutional context that we can look at to account for cross-country differences. Any argument tracing back a gap in the participation rate as high as 40 percentage points to a single cause would be over simplified. Our aim is to ascertain which are the areas where the action is, to decompose the issue for further research.

The chapter is structured as follows. In next section we start comparing in a static view some facts about older workers' employment status, personal, and family characteristics across European countries. We consider some of the factors that are usually held to be important in shaping labour market participation, such as the educational attainment level of the individuals, or the diffusion of part time work. Their distribution and their impact - although not always significative in a multivariate analysis - provide a first rationale for cross-country differences in participation profiles.

The most insightful hints however emerge focussing on the basic labour market transitions the individuals undergo ${ }^{1}$. The key reason for do so is that the participation of the elders can conveniently be viewed as the result of several basic labour market transitions - the transition from employment to retirement is the most obvious, but not the only one. It is important, moreover, to study the relevant transitions in a life course perspective. The existing low employment rates, actually, can be the effect of choices made in the past, or - in presence of market frictions and/or rigidities in the legislation - it can be a long lasting consequence of events happened in the past. In section two we will consider two selection processes of this kind. The first is (mostly) about female

\footnotetext{
${ }^{1}$ A deal of research with this focus has been delivered within the TLM.NET Thematic Network (funded by the $5^{\text {th }}$ framework programme of the European Commission) who sponsor a "TLM (Transitional Labour Market) approach". Reference papers on the this research programme can be found on the website http://www.siswo.uva.nl/tlm.
} 
participation. In past decades, when average household size in Italy was pretty higher than today, many females took the life cycle decision of not participating to the labour market, and to offer their working effort within the household for child and family care. The second selection process is the combined effect of retirement rules and labour market policies that in past decades were biased towards early retirement, and a legislation that restrained the possibility for individuals to have a dependent job once they were pension holders. Early retirement schemes and restrictions in pension holders' labour offer, taken together, imply the filtering out of able workers from the labour market. Both selection processes seem to have a large role in explaining actual low participation rates of the elders in several European countries, and particularly in Italy.

\section{A static view}

The issue of low participation of the elders in Europe is easily sketched. In figure 1 the participation rate of individuals in the age bracket 55-64 is plotted for a selection of European Countries. At the beginning of the Nineties 13 out of 16 countries selected were below the 50\% target set up in Stockholm by the European Commission. The dynamics registered in the subsequent decade has generally been a positive one, in some cases (Netherlands, Finland, Ireland) with an increase of more than ten percentage points. The increases notwithstanding, in 2002 about half of the countries considered still had figures largely below the target, some of them standing worryingly below $30 \%$.

Figure 1. Employment rates for people aged 55-64. 1990-2002.

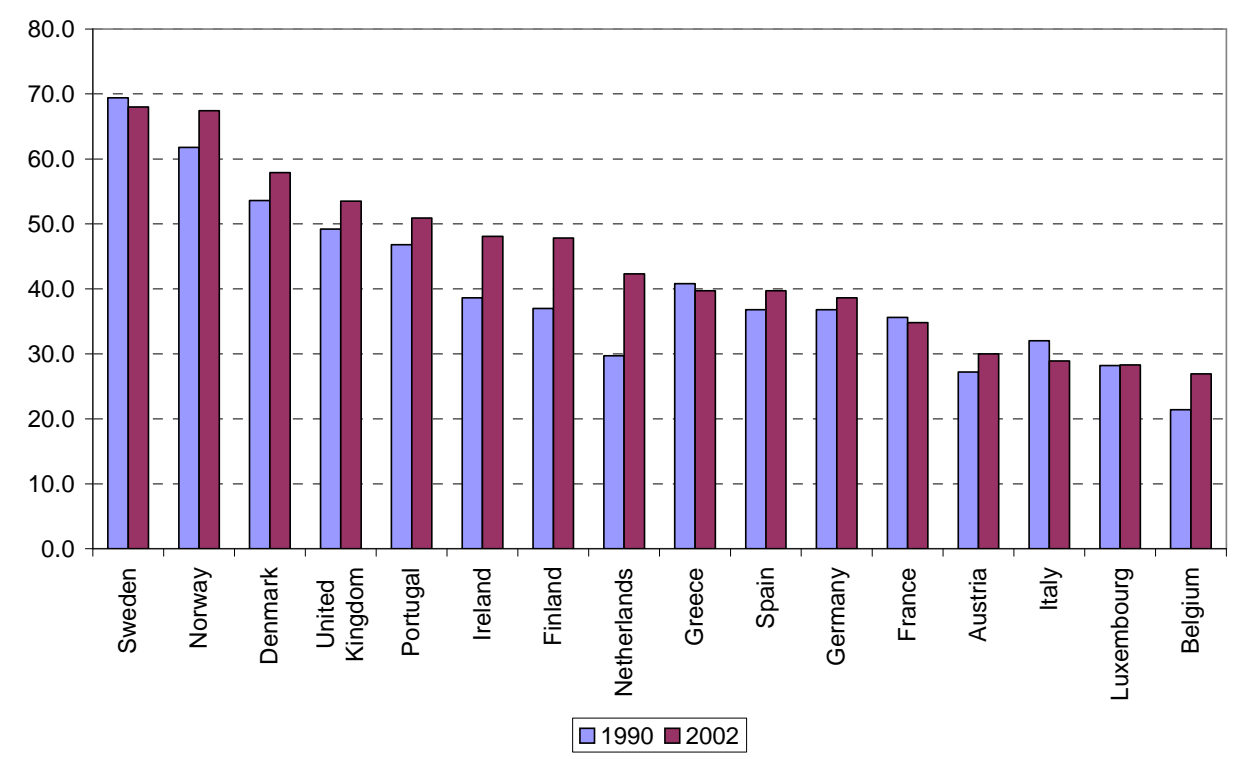

As regards men, in many countries the employment rate has been decreasing (see Figure 2). The decline has been substantial in Italy, France and Germany, the best performers being Netherlands, Finland and Ireland. In contrast, females have shown almost everywhere a highly positive dynamics, offsetting in most cases the decline occurred for males. The issue, as regards women, is about the absolute values recorded in many countries. Italy, in 2002, had the worst score, with a female employment rate as low as $18 \%$. 
Figure 2. Employment rates for people aged 55-64. 1990-2002.

Male

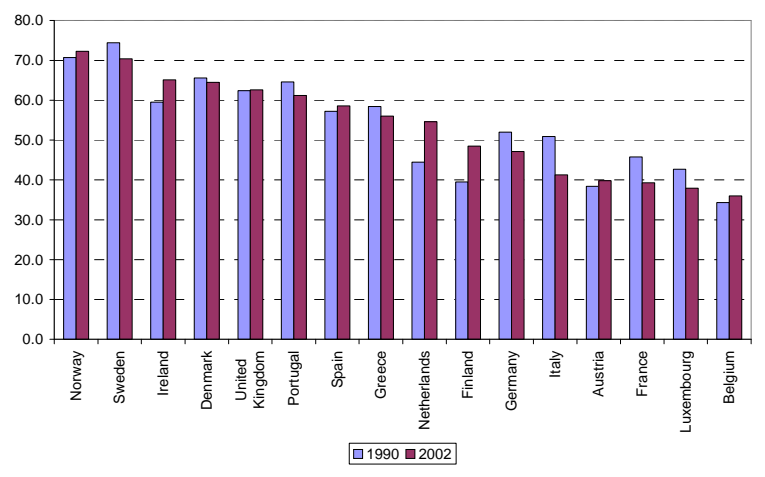

Female

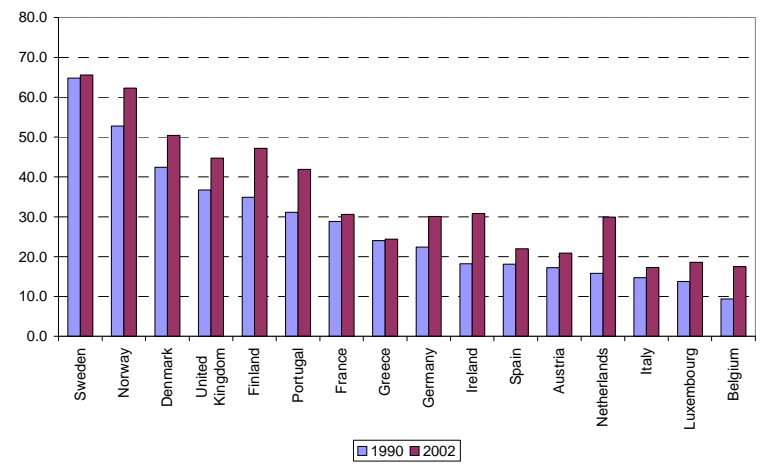

There are many characteristics of the individuals, of their working careers, of the labour demand and of the cultural and institutional context that we can look at to account for cross-country differences. At the individual level it is widely documented the positive relationship between the educational attainment level of older workers and their employment rate.

In table 1 the employment rates by educational level are ranked over the EU152. Not surprisingly, there is not a great variability in the employment rate of the most educated (the coefficient of variation is as low as 5.5\%). Large cross-country differences emerge as regards the lowest educated (the coefficient of variation is $17.5 \%$ ). Here we go from over $74 \%$ in Sweden, to $40.1 \%$ for Italy, the lowest value in the ranking.

Also, the actual composition of the elderly population by educational level shows big differences across countries. In Mediterranean countries, plus Austria, the share of the most educated (Isced levels 5-7) is below $10 \%$ of all people aged 55-64 (see Table 2). In the same countries, without Austria, also the share of elders with second stage level is particularly low.

These figures can be explained with the higher employability granted by a higher human capital, and to the probable lower disutility of work associated with high-skill jobs, but they may hide also a composition effect, linked to the accrued seniority. The higher the education attainment level, the later the entry in the labour market, and the lower the accrued seniority - a fact that in most pension systems implies an incentive or the obligation to lengthen the contribution period. Later on we will control for this. What we can say by now is this: in most countries the issue is not the low participation rate of high educated elders, but the fact that many elders have a low average education level, and low educated tend to participate low.

In Italy and Spain this pattern is particularly clear. In both countries the elders with a third level educational attainment have participation rates in line with other countries $-83 \%$ and $82.6 \%, 7^{\text {th }}$ and $8^{\text {th }}$ in the ranking respectively. But they are not a large target group, since in the educational level distribution their share is as low as $4 \%$ and $8 \%$ respectively. At the same time, the share of elders with a less than second stage educational level is particularly high $(84 \%$ and $77 \%$ respectively), and their participation rates are among the lowest $\left(42.3 \%\right.$ and $48.3 \%, 14^{\text {th }}$ and $12^{\text {th }}$ respectively).

\footnotetext{
${ }^{2}$ The Stockholm target defined by the European Commission is referred to the 55-64 age group; in the following analysis we will occasionally consider the 50-64 age group for sample size reasons.
} 
Table 1. Employment rates by educational attainment level, people aged 50-59, 2002 (ranking in parenthesis)

\begin{tabular}{ccccccccc}
\hline \multirow{2}{*}{ Males and females } & \multicolumn{9}{c}{ All 50-59 years } & \multicolumn{3}{c}{ Less than secondary } & Upper secondary level (M) & \multicolumn{2}{c}{ Third level (H) } \\
\hline S & 82 & $(1)$ & 74.4 & $(1)$ & 81.8 & $(1)$ & 91.2 & $(1)$ \\
DK & 79.5 & $(2)$ & 66 & $(4)$ & 80.3 & $(2)$ & 88.2 & $(3)$ \\
UK & 71.5 & $(4)$ & 53.6 & $(7)$ & 76.3 & $(3)$ & 82.5 & $(9)$ \\
P & 67.8 & $(6)$ & 66.3 & $(2)$ & 74.1 & $(4)$ & 85.2 & $(4)$ \\
IRL & 61.4 & $(9)$ & 52.5 & $(9)$ & 68 & $(9)$ & 80.2 & $(11)$ \\
FIN & 73.1 & $(3)$ & 66.3 & $(2)$ & 71.9 & $(6)$ & 84.1 & $(5)$ \\
NL & 68.5 & $(5)$ & 55.7 & $(6)$ & 74.1 & $(4)$ & 83.5 & $(6)$ \\
E & 54.5 & $(13)$ & 48.3 & $(12)$ & 64.3 & $(11)$ & 82.6 & $(8)$ \\
D & 67.6 & $(7)$ & 51.9 & $(10)$ & 68.2 & $(8)$ & 82.4 & $(10)$ \\
EL & 55.4 & $(12)$ & 53 & $(8)$ & 51.7 & $(15)$ & 76 & $(14)$ \\
F & 65.3 & $(8)$ & 56.7 & $(5)$ & 69.2 & $(7)$ & 79.5 & $(12)$ \\
A & 61.1 & $(10)$ & 49.8 & $(11)$ & 61.8 & $(12)$ & 79.5 & $(12)$ \\
I & 51.5 & $(15)$ & 42.3 & $(14)$ & 67.4 & $(10)$ & 83 & $(7)$ \\
L & 56.4 & $(11)$ & 43.3 & $(13)$ & 59.4 & $(14)$ & 89.1 & $(2)$ \\
B & 52.8 & $(14)$ & 40.1 & $(15)$ & 60.6 & $(13)$ & 73.2 & $(15)$ \\
\hline
\end{tabular}

Source: Eurostat LFS 2002

In table 2 we report the distribution of some other variables that can have a role in our argument. First, household size. Mediterranean countries, plus Ireland, are places where the elderly seldom live alone. Roughly $60 \%$ of them live in families composed by at least three members. This may imply a lower need to work, and/or lower time available to participate to the labour market because of family care burdens.

As regards the latter, Italians and Belgians seem to be the more involved. When asked whether they have to look after children or some other members of the family, roughly one out of four of them responded yes (section "Family care" in table 2). This is coherent with Oecd (2004) that indicates family responsibilities as a major factor behind the non-participation to the labour market of Italian women.

Note also that in most countries the elderly who are engaged in child care report a rather high burden associated to this activity. When asked how many hours per week they spent in childcare, elders in Ireland, Greece, Spain and Portugal reported a burden close to a full time work in 43-46\% of cases. 
Table 2. Distribution of people aged 55-64 by Educational level, Household size, Family and child care (year 2000)

\begin{tabular}{|c|c|c|c|c|c|c|c|c|c|c|c|c|c|c|c|}
\hline & $\mathrm{D}$ & NL & $\mathrm{B}$ & $\mathrm{F}$ & IRL & $\mathrm{I}$ & EL & $\mathrm{E}$ & $\mathrm{P}$ & A & FIN & $\mathrm{S}$ & G & $\mathrm{L}$ & UK \\
\hline \multicolumn{16}{|l|}{ Education } \\
\hline Third level (Isced 5-7) & $25 \%$ & - & $23 \%$ & $16 \%$ & $13 \%$ & $4 \%$ & $8 \%$ & $9 \%$ & $4 \%$ & $4 \%$ & $25 \%$ & $22 \%$ & $21 \%$ & $10 \%$ & $35 \%$ \\
\hline Second stage (Isced 3) & $42 \%$ & - & $35 \%$ & $6 \%$ & $24 \%$ & $17 \%$ & $13 \%$ & $6 \%$ & $2 \%$ & $59 \%$ & $33 \%$ & $44 \%$ & $55 \%$ & $32 \%$ & $10 \%$ \\
\hline Less than second stage (Isced $0-2$ ) & $31 \%$ & - & $40 \%$ & $77 \%$ & $62 \%$ & $77 \%$ & $77 \%$ & $84 \%$ & $92 \%$ & $36 \%$ & $40 \%$ & $32 \%$ & $23 \%$ & $57 \%$ & $54 \%$ \\
\hline \multicolumn{16}{|l|}{ Household size } \\
\hline One member & $19 \%$ & $14 \%$ & $17 \%$ & $13 \%$ & $7 \%$ & $6 \%$ & $4 \%$ & $6 \%$ & $6 \%$ & $11 \%$ & $16 \%$ & $13 \%$ & $11 \%$ & $10 \%$ & $13 \%$ \\
\hline Two members & $70 \%$ & $65 \%$ & $55 \%$ & $60 \%$ & $30 \%$ & $26 \%$ & $37 \%$ & $28 \%$ & $37 \%$ & $50 \%$ & $62 \%$ & $75 \%$ & $58 \%$ & $47 \%$ & $57 \%$ \\
\hline Three members & $8 \%$ & $13 \%$ & $17 \%$ & $18 \%$ & $22 \%$ & $30 \%$ & $28 \%$ & $26 \%$ & $28 \%$ & $18 \%$ & $16 \%$ & $7 \%$ & $19 \%$ & $23 \%$ & $18 \%$ \\
\hline Four or more members & $2 \%$ & $5 \%$ & $9 \%$ & $7 \%$ & $39 \%$ & $36 \%$ & $29 \%$ & $39 \%$ & $28 \%$ & $19 \%$ & $5 \%$ & $3 \%$ & $11 \%$ & $18 \%$ & $10 \%$ \\
\hline \multicolumn{16}{|l|}{ Family care } \\
\hline Looking after children & $7 \%$ & $13 \%$ & $20 \%$ & $10 \%$ & $10 \%$ & $21 \%$ & $9 \%$ & $7 \%$ & $7 \%$ & $10 \%$ & $8 \%$ & - & $7 \%$ & - & $0 \%$ \\
\hline Looking after a person & $6 \%$ & $7 \%$ & $9 \%$ & $5 \%$ & $3 \%$ & $6 \%$ & $4 \%$ & $6 \%$ & $5 \%$ & $6 \%$ & $9 \%$ & - & $2 \%$ & - & $24 \%$ \\
\hline Looking after a child and a person & $1 \%$ & $2 \%$ & $2 \%$ & $1 \%$ & $1 \%$ & $3 \%$ & $1 \%$ & $1 \%$ & $1 \%$ & $1 \%$ & $1 \%$ & - & $0 \%$ & - & \\
\hline Not looking after any person & $84 \%$ & 77 & $67 \%$ & $83 \%$ & $84 \%$ & $68 \%$ & $85 \%$ & $84 \%$ & $86 \%$ & $82 \%$ & $81 \%$ & & $89 \%$ & & $74 \%$ \\
\hline \multicolumn{16}{|l|}{ Hours per week spent in child care } \\
\hline Less than 14 hours & $69 \%$ & $32 \%$ & $62 \%$ & $55 \%$ & $28 \%$ & $29 \%$ & $16 \%$ & $17 \%$ & $24 \%$ & $39 \%$ & $52 \%$ & - & - & - & - \\
\hline 14 up to 28 hours & $12 \%$ & $56 \%$ & $25 \%$ & $26 \%$ & $24 \%$ & $33 \%$ & $39 \%$ & $36 \%$ & $32 \%$ & $47 \%$ & $35 \%$ & - & - & - & - \\
\hline More than 28 hours & $18 \%$ & $11 \%$ & $12 \%$ & $18 \%$ & $46 \%$ & $37 \%$ & $44 \%$ & $45 \%$ & $43 \%$ & $13 \%$ & $12 \%$ & - & - & - & - \\
\hline
\end{tabular}

Source: Our elaborations on Echp, wave 7 
Table 3. Employment of people aged $>50$ by economic activity (percentages)

Agriculture, hunting and forestry, fishing

Mining and quarrying, electricity, gas and water supply

Manufacture of food, beverages and tobacco

Manufacture of textiles, clothing and leather

Manufacture of wood and paper; publishing and printing

Manufacture of coke, petroleum, chemicals, rubber etc..

Manufacture of metal, machinery and equipment n.e.c.

Other manufacture

Construction

Wholesale and retail trade; repair of vehicles etc.

Hotels and restaurants

Transport, storage and communication

Financial intermediation

Real estate, renting and business activities

Public administration and defence; social security

Education

Health and social work

Other community, social and personal service activities

\begin{tabular}{rrrrrrrrrrrrrrr} 
S & \multicolumn{1}{r}{ D } & \multicolumn{1}{l}{ UK } & \multicolumn{1}{r}{ P } & \multicolumn{1}{l}{ IRL } & \multicolumn{1}{l}{ FIN } & \multicolumn{1}{l}{ NL } & \multicolumn{1}{l}{ EL } & \multicolumn{1}{l}{ E } & \multicolumn{1}{l}{ A } & \multicolumn{1}{l}{ I } & \multicolumn{1}{l}{ B* } & \multicolumn{1}{l}{ avg } \\
4.8 & 3.8 & 2.0 & 41.8 & 27.6 & 17.7 & 4.6 & 36.0 & 14.2 & 5.3 & 20.3 & $\mathbf{1 0 . 1}$ & 4.8 & 1.7 & 15.9 \\
1.2 & 1.1 & 0.9 & 0.4 & 1.5 & 0.2 & 1.0 & 1.8 & 0.9 & 1.1 & 2.8 & $\mathbf{2 . 3}$ & 0.9 & 1.7 & 1.2 \\
2.1 & 2.5 & 1.9 & 2.1 & 2.6 & 1.5 & 1.9 & 1.5 & 3.2 & 1.8 & 1.5 & $\mathbf{2 . 6}$ & 0.5 & 1.7 & 2.1 \\
0.5 & 1.1 & 1.1 & 2.8 & 0.6 & 0.7 & 1.2 & 2.7 & 2.2 & 1.2 & 1.6 & $\mathbf{2 . 4}$ & 0.0 & 1.7 & 1.6 \\
4.6 & 2.1 & 2.2 & 1.3 & 1.8 & 6.9 & 2.1 & 0.8 & 2.3 & 1.4 & 1.2 & $\mathbf{2 . 0}$ & 1.4 & 1.7 & 2.2 \\
2.5 & 2.1 & 2.9 & 1.3 & 1.7 & 2.0 & 2.3 & 1.2 & 3.2 & 3.3 & 1.0 & $\mathbf{2 . 7}$ & 4.8 & 1.7 & 2.3 \\
6.5 & 4.4 & 3.4 & 1.8 & 1.0 & 2.7 & 3.3 & 1.4 & 3.9 & 4.0 & 4.9 & $\mathbf{3 . 5}$ & 9.2 & 3.3 & 3.6 \\
6.9 & 3.2 & 4.4 & 0.7 & 2.2 & 2.7 & 3.6 & 2.0 & 2.8 & 4.9 & 3.8 & $\mathbf{3 . 1}$ & 0.7 & 1.7 & 3.3 \\
4.3 & 7.6 & 6.4 & 6.5 & 6.5 & 6.6 & 5.7 & 7.9 & 9.1 & 6.7 & 6.6 & $\mathbf{7 . 1}$ & 7.6 & 6.7 & 6.7 \\
9.2 & 7.4 & 13.9 & 11.6 & 7.3 & 9.8 & 10.4 & 12.6 & 13.9 & 10.0 & 10.2 & $\mathbf{1 5 . 0}$ & 7.4 & 13.3 & 11.2 \\
1.9 & 1.3 & 6.1 & 4.7 & 3.0 & 2.7 & 1.4 & 5.2 & 4.3 & 2.4 & 2.3 & $\mathbf{2 . 5}$ & 2.3 & 5.0 & 3.3 \\
7.2 & 6.5 & 6.4 & 3.2 & 5.9 & 6.1 & 5.6 & 5.8 & 6.5 & 6.8 & 4.8 & $\mathbf{5 . 7}$ & 8.5 & 8.3 & 5.9 \\
1.9 & 2.8 & 2.8 & 1.1 & 1.8 & 2.7 & 3.7 & 1.0 & 1.9 & 2.9 & 4.1 & $\mathbf{2 . 3}$ & 10.6 & 5.0 & 2.5 \\
10.5 & 5.3 & 10.7 & 2.5 & 4.6 & 8.8 & 8.7 & 1.5 & 4.9 & 7.6 & 4.0 & $\mathbf{4 . 2}$ & 3.9 & 5.0 & 6.0 \\
8.7 & 10.4 & 6.2 & 5.5 & 6.4 & 4.4 & 10.0 & 5.3 & 7.6 & 11.0 & 11.4 & $\mathbf{9 . 1}$ & 14.3 & 3.3 & 8.1 \\
10.8 & 12.2 & 10.8 & 4.3 & 9.9 & 5.6 & 11.7 & 5.4 & 7.0 & 13.0 & 5.9 & $\mathbf{1 2 . 1}$ & 8.1 & 8.3 & 9.1 \\
10.7 & 19.9 & 12.5 & 3.1 & 9.0 & 12.8 & 15.0 & 3.6 & 3.7 & 11.1 & 7.4 & $\mathbf{6 . 6}$ & 6.2 & 6.7 & 8.6 \\
5.8 & 6.3 & 5.3 & 5.4 & 6.6 & 5.9 & 7.7 & 4.2 & 8.4 & 5.7 & 6.1 & $\mathbf{6 . 6}$ & 8.5 & 23.3 & 6.3
\end{tabular}


Tables 3-4 compare two aspects closer to institutional issues and to the demand side of the market. It is often claimed that a way to increase elders' employability is to increase parttime job opportunities and employment in the social and personal services sector. Actually, as regards to the latter, in Italy the share of workers employed in such sectors is above the European average. In general, while the international differences are sometimes wide - it is the case of the share of elders employed in the agricultural sector - there is not a clear path linking sectoral distribution of the elders and high participation rate.

As regards the first point, the correlation between high participation and the diffusion of part-time work seems clearer. The three EU15 member countries with the highest elders' participation rate - Sweden, Denmark and United Kingdom - are also among the countries where part time work is more popular. They rank $3^{\text {rd }}, 8^{\text {th }}$ and $2^{\text {nd }}$ respectively as regards workers in the 50-64 age bracket, and $2^{\text {nd }}, 6^{\text {th }}$ and $3^{\text {rd }}$ as regards workers over 65 . In almost all countries, moreover, a large majority of people over 65 who are still working do so with a part time occupation.

In Italy and in the other Mediterranean countries, the diffusion of part time work is low for all age brackets, and particularly low for the older ones.

Table 4. Part-time as a percentage of each age group total employment 2002 (ranking in parenthesis)

\begin{tabular}{|c|c|c|c|c|c|c|c|c|c|c|}
\hline \multirow[b]{2}{*}{$\mathrm{S}$} & \multicolumn{2}{|c|}{ 15-24years } & \multicolumn{2}{|c|}{$25-49$ years } & \multicolumn{2}{|c|}{ 50-64 years } & \multicolumn{2}{|c|}{$65+$ years } & \multicolumn{2}{|c|}{$15-64$ years } \\
\hline & 41 & (3) & 15.6 & (6) & 22.2 & (3) & 76.1 & (2) & 20.4 & (3) \\
\hline DK & 50.3 & (2) & 14.4 & (8) & 17.1 & (8) & 57.6 & (6) & 20 & (5) \\
\hline UK & 33.4 & (5) & 20.5 & (3) & 28.3 & (2) & 73.5 & (3) & 24.1 & (2) \\
\hline $\mathrm{P}$ & 7.3 & (14) & 5.9 & (14) & 16 & (10) & 55.4 & (7) & 8.3 & (13) \\
\hline IRL & 21.2 & (6) & 13.7 & (9) & 20.3 & (5) & 30.9 & (11) & 16.3 & (8) \\
\hline FIN & 34.1 & (4) & 7.5 & (12) & 12.9 & (11) & 63.1 & (4) & 12.1 & (10) \\
\hline NL & 64 & (1) & 38.2 & (1) & 42.8 & (1) & 84.2 & (1) & 43.4 & (1) \\
\hline E & 13.4 & (10) & 7.4 & (13) & 6.6 & (14) & 16.4 & (12) & 7.9 & (14) \\
\hline D & 13.5 & (9) & 20.9 & (2) & 22.2 & (3) & 61.5 & (5) & 20.3 & (4) \\
\hline EL & 7.4 & (13) & 3.7 & (15) & 4.5 & (15) & 15.4 & (13) & 4.2 & (15) \\
\hline $\mathrm{F}$ & 20.1 & (7) & 15.3 & (7) & 16.7 & (9) & 48.1 & (9) & 16.1 & (9) \\
\hline A & 10.1 & (11) & 20.3 & (4) & 17.4 & (7) & 54.7 & (8) & 18.5 & (7) \\
\hline I & 9.6 & (12) & 8.9 & (11) & 6.7 & (13) & 14.6 & (14) & 8.5 & (12) \\
\hline $\mathrm{L}$ & 6.2 & (15) & 12.6 & (10) & 9.9 & (12) & & & 11.6 & (11) \\
\hline B & 17.7 & (8) & 19.3 & (5) & 20 & (6) & 46.4 & (10) & 19.3 & (6) \\
\hline
\end{tabular}

Source: Eurostat LFS 2002

\section{Multivariate analysis}

In order to control for possible composition effects, we tested the impact of different individual characteristics on the employment status of the elderly with a multivariate analysis. We used the first 7 waves of the ECHP to estimate a simple logit model for the probability to be in the labour force (no matter if employed or unemployed) for people aged $50-64^{3}$. We adopt the standard ILO classification to discriminate between individuals in the labour force (employed and not employed), and inactive or out of the labour force. We are mainly

\footnotetext{
${ }^{3}$ The model is a standard logit model of the form $p(X)=\exp \left(\alpha+\beta^{\prime} X\right) /\left[1+\exp \left(\alpha+\beta^{\prime} X\right)\right]$, where $\alpha$ and $\beta$ are parameters to be estimated and $X$ is a vector of covariates

${ }^{4}$ The employed are those whose current activity is paid employment, paid apprenticeship, or training under special schemes related to employment or self-employment. This definition of employment excludes those currently working less than 15 hours per week. Following the ILO definition, the unemployed are those who are
} 
interested in documenting cross-country differences in the characteristics of the participation process and how it depends on observable individual characteristics and family structure. For this reason the employed and the unemployed are taken together in the model, because both express a desire to participate to the labour market, and are contrasted with the inactive. By now, we take into account also individuals who have never worked, however, the presence of persons who have never worked is another important element in explaining the participation rate differences across countries; we will get back to this point in next section.

The model, fitted separately by gender and country, for which we pool all the available waves $^{5}$, includes among the explicative age, education ( 2 dummies, one for college and one for secondary education), an indicator for people without spouse, the number of children aged less than 16, health status, the level of equivalised household income in PPP in previous year ${ }^{6}$, a dummy if the individual is involved in child or other person (old, ill, disabled) care activities and time dummies.

The intercept of the model correspond to a man aged 55 employed in 1994 with only primary education completed, with a wife without children aged less then 16 , with a medium degree of health, who has no family care burdens.

Estimates are computed using the cross-sectional personal weights. These weights are introduced to correct for sampling design, household nonresponse, and unit nonresponse within responding households. Moreover standard errors are corrected in order to take into account the correlation within the individuals among the different waves pooled.

\footnotetext{
looking for a job, are ready to work and have carried out some active search activity in the last month. The inactive are those who are neither employed nor unemployed.

${ }^{5}$ For all countries except Netherlands we pool 7 waves corresponding to years 1994-2000. For the Netherlands, due to some problems in the data, we consider only years 1998-2000.

${ }^{6}$ To capture possible non linear effects of income on participation, we included a linear and a squared term. We use the lagged value of equivalised household income in order to circumvent the endogeneity of current personal income to participation.
} 


\section{Main results}

For both men and women, participation probabilities decrease with age, but for some countries, mainly Ireland and Portugal, the age effect is not huge (see regression results in the Appendix ${ }^{7}$ ).

After controlling for the individual characteristics, the positive relationship between education and participation vanishes in some countries (Denmark, Netherlands, UK, Portugal, for men and Netherlands and France for women). It is strong in Italy and Belgium for men and in Belgium, Denmark, Ireland, Italy and Spain for women. In Greece, for both men and women, and in Spain for men, participation probabilities decrease with school attainment and are significantly lower for the middle-educated. This result is in line with what was reported by Nicoletti and Peracchi (2001) on the probability for the elder (50-69 aged) to be employed.

The separately estimation by gender allow us to clear detect the effect of the family structure on the participation status of men and women: not having a spouse tends to reduce the probability of being in the labour force for men, whereas for women the effect is just the opposite. In a similar way goes the presence of children; they increase the participation of men, while their effect is different by countries for women: in most countries they do not affect the participation probabilities, they increase the probability of women of being in the labour force in Netherlands and Portugal, they reduce it in UK and Italy.

Not surprisingly, health status has a large impact on participation in all European countries. The impact of bad health is negative, and the impact of good health is positive, sign that the working ability of the benchmark individual are already hampered by its medium degree of health. Note that the actual effect of bad health could be overestimated in case of justification bias (see Ruhm [1989]): for older people, it is more easy to declare having health problem, even if the point is a "leisure preference".

In most of the countries considered household income is highly correlated with the participation status of both men and women. Income does not affect older male participation in Netherlands, Irelands and Portugal, and female participation in Germany, Denmark, Ireland and Portugal. In all the other countries the linear term included in the regression is negative and the squared one is positive ${ }^{8}$. Plotting income against the combined effect of the two terms, the overall effect - with the only exception of Portugal for which is decreasing- is a Ushaped one: in the low tail of the income distribution participation increases as income decreases, due to the relationship between wages and pension; in the higher tail of the distribution instead, participation increases with income, signalling a non-disutility of work.

Being involved in child care activities significantly decreases the male and female participation probabilities of the elderly in almost all countries, with the only exclusion of Denmark and Netherlands and Portugal only for men. But the magnitude is different, ranging, for men, from a reduction in the probabilities ${ }^{9}$ of $-71 \%$ in Spain and $-66 \%$ in UK to the smallest negative effect found in Italy (-40\%); for women range goes from $-63 \%$ in UK and $49 \%$ in France, to $-19 \%$ in Italy (Table 5).

\footnotetext{
${ }^{7}$ The reported statistics in tables A1-A2 concerning estimated models' quality show a good adequacy of the overall model in most countries and especially for men. For women, although lower values in the indicators of association of predicted probabilities to observed responses indicate the presence of some other factors that our model does not control for, the estimates confirm the importance of individual and household characteristics on the employment status.

${ }^{8}$ Exceptions are found among women in Belgium and UK where only the linear term is significant with a positive sign.

${ }^{9}$ These percentages are computed by the odds ratio that gives the increase or decrease in probability that a unit change in the independent variable has in the participation probability.
} 
Analogously negative effects in participation probabilities of men and women are found when the elderly are engaged in elder care activities. This effect is significant in most countries when looking at the female regression, is significant only in France, UK, Ireland and Italy, when looking at the male regression. Moreover it is lower than that associated with child care, with the exception of Italy where elder care activities seems to cause a stronger hindrance to participation in the labour market than child care.

\section{Table 5. Percentage reduction in participation probabilities due to child and elder care activities}

\begin{tabular}{lcccc} 
& \multicolumn{2}{c}{ Men } & \multicolumn{2}{c}{ Women } \\
Germany & child care & elder care & child care & elder care \\
Denmark & $47.7 \%$ & n. s. & $33.4 \%$ & n. s. \\
NL & n. s. & n. s. & n. s. & $30.0 \%$ \\
Belgium & n. s. & n. s. & n. s. & $40.9 \%$ \\
France & $61.3 \%$ & n. s. & $47.8 \%$ & n. s. \\
UK & $59.9 \%$ & $43.8 \%$ & $48.9 \%$ & $33.9 \%$ \\
Ireland & $64.6 \%$ & $45.4 \%$ & $63.5 \%$ & $23.5 \%$ \\
Italy & $46.9 \%$ & $48.5 \%$ & $37.5 \%$ & n. s. \\
Greece & $39.6 \%$ & $59.6 \%$ & $18.6 \%$ & $45.7 \%$ \\
Spain & $39.0 \%$ & n. s. & $37.8 \%$ & n. s. \\
Portugal & $71.5 \%$ & n. s. & $41.7 \%$ & $26.6 \%$ \\
Source & n. s. & n. s. & $47.7 \%$ & n. s.
\end{tabular}

Source: Our elaborations on ECHP data

Note: n.s.= not significant

\section{A life course perspective}

In previous section we showed the empirical correlations that can be detected between some personal and institutional characteristics and the labour market participation of the elders. This kind of static analysis has some pitfalls that can be overcome adopting the Transitional Labour Market (TLM) approach. The key reason to do this is that participation of the elders can be conveniently viewed as the result of several basic labour market transitions - from employment to retirement, from employment to unemployment to retirement, from inactivity to employment, and so on. It is focusing on these transitions that we may ask whether they had a voluntary nature or they point to an employability issue, and hence whether they involve a social risk that should be managed.

It is important, moreover, to implement the TLM approach within a life course perspective, that provides the correct analytical framework for the analysis of social phenomena taking into account life events. The simple but compelling reason to do this is that existing low employment rates can be the effect of choices made (or of events happened) in the past. A first instance regards women. A low employment rate observed today can be the consequence of a once-and-for-all choice - made in the past - to offer their work within the family rather than in the labour market. As we will show this selection process is empirically relevant in most European countries, and particularly in Italy. The policy relevance of this evidence has to be stressed from the outset. It is important to consider the elder person who never worked as a separate target group for the policy maker. For some of them, nonparticipation is simply a consequence of a life cycle participation choice made in the past, and there are no employability issues about this. On the opposite, for some others who never 
worked but who may want to participate, the employability issue is potentially more challenging, due to possible attritions in their late entry in the labour market.

The second selection process has to do with the transition from work to retirement. In Italy, in past decades, retirement rules and labour market policies had a strong bias towards early retirement (Blondal and Scarpetta 1998; 1999). On top of this, the labour market regulations restrained the possibility for individuals to have a dependent job once they were pension holders. The latter is an institutional setting that can have, and probably had, a perverse effect in the labour market, since it converts retirement into an absorbing state. As we will show, early retirement schemes plus restrictions in pension holders' labour offer had a long lasting impact on the participation behaviours, since it implied the filtering out of many able workers from the labour market.

\section{The family care selection process}

Table 6 compares the overall employment rates for the elder with the figures that come out when we exclude those who never worked. By construction, since we are selecting out people who are not working, the employment rates increase in all countries. The size of the increase however reveals large differences across Europe. Netherlands is the country showing the highest increase, both for males and females ( 7 and 18 percentage points respectively) ${ }^{10}$. Actually, it is the only country where the selection is sizeable for men. Besides the Netherlands, the selection effect is relevant in all Southern European Countries. In Italy, when we exclude those who have never worked, female employment rate increases by almost 10 percentage points, going from $17.5 \%$ to $27.3 \%$.

Table 6. Employment rates for the elderly (55-64 years old), overall vs. those who never worked, year 2000

\begin{tabular}{|c|c|c|c|c|c|c|c|c|c|}
\hline \multirow[b]{3}{*}{ Austria } & \multicolumn{3}{|c|}{ All } & \multicolumn{3}{|c|}{ Men } & \multicolumn{3}{|c|}{ Women } \\
\hline & $\begin{array}{c}\text { employment } \\
\text { rate }\end{array}$ & $\begin{array}{c}\text { w/o who } \\
\text { never worked }\end{array}$ & $\Delta$ & $\begin{array}{c}\text { employment } \\
\text { rate }\end{array}$ & $\begin{array}{c}\text { w/o who } \\
\text { never worked }\end{array}$ & $\Delta$ & $\begin{array}{c}\text { employment } \\
\text { rate }\end{array}$ & $\begin{array}{c}\text { w/o who } \\
\text { never worked }\end{array}$ & $\Delta$ \\
\hline & $22.7 \%$ & $23.9 \%$ & 1.2 & $29.8 \%$ & $29.9 \%$ & 0.1 & $16.4 \%$ & $17.9 \%$ & 1.6 \\
\hline Belgium & $33.4 \%$ & $36.2 \%$ & 2.8 & $47.2 \%$ & $47.9 \%$ & 0.7 & $20.7 \%$ & $23.7 \%$ & 3.0 \\
\hline Denmark & $59.0 \%$ & $59.7 \%$ & 0.7 & $68.6 \%$ & $68.8 \%$ & 0.2 & $50.2 \%$ & $51.3 \%$ & 1.1 \\
\hline Finland & $49.7 \%$ & $49.8 \%$ & 0.1 & $49.0 \%$ & $49.0 \%$ & 0.0 & $50.4 \%$ & $50.6 \%$ & 0.3 \\
\hline France & $31.3 \%$ & $32.6 \%$ & 1.2 & $37.7 \%$ & $38.8 \%$ & 1.1 & $25.5 \%$ & $26.6 \%$ & 1.1 \\
\hline Germany & $43.0 \%$ & $43.1 \%$ & 0.1 & $50.5 \%$ & $50.5 \%$ & 0.0 & $35.4 \%$ & $35.5 \%$ & 0.1 \\
\hline Greece & $39.6 \%$ & $46.4 \%$ & 6.8 & $58.5 \%$ & $59.2 \%$ & 0.7 & $22.3 \%$ & $30.5 \%$ & 8.3 \\
\hline Ireland & $48.9 \%$ & $50.8 \%$ & 1.9 & $70.3 \%$ & $71.0 \%$ & 0.7 & $28.6 \%$ & $30.7 \%$ & 2.1 \\
\hline Italy & $31.0 \%$ & $38.0 \%$ & 7.0 & $44.8 \%$ & $45.2 \%$ & 0.4 & $17.5 \%$ & $27.3 \%$ & 9.8 \\
\hline Portugal & $51.1 \%$ & $56.8 \%$ & 5.7 & $64.6 \%$ & $65.4 \%$ & 0.7 & $39.6 \%$ & $48.1 \%$ & 8.5 \\
\hline Spain & $35.6 \%$ & $41.5 \%$ & 5.9 & $52.8 \%$ & $53.3 \%$ & 0.5 & $19.7 \%$ & $26.9 \%$ & 7.2 \\
\hline NL & $43.8 \%$ & $57.2 \%$ & 13.4 & $54.4 \%$ & $61.5 \%$ & 7.0 & $33.5 \%$ & $51.8 \%$ & 18.3 \\
\hline UK & $51.9 \%$ & $53.4 \%$ & 1.4 & $61.4 \%$ & $62.2 \%$ & 0.8 & $43.9 \%$ & $45.7 \%$ & 1.7 \\
\hline
\end{tabular}

\section{The early retirement selection process}

The second selection process that we sketched is likely to be evident in institutional contexts were both early retirement is - or has been - common, and the labour regulations impose - or imposed - limits to the employment of pension holders. Italy meets both conditions, and can be considered a clear case study of this selection process.

\footnotetext{
${ }^{10}$ This quite surprising result can hide missing data problem in the ECHP dataset
} 
In the retirement legislation that was active up to 1992 there were two aspects that represented a bias towards early retirement. First, the eligibility criteria for seniority pensions were loose, particularly for women and in the public sector. Second, the pension benefit calculation rules were not linked to the actual age of retirement, so that from an actuarial point of view they were the more convenient the earlier the worker decided to retire. In 1992 and 1995 the retirement legislation has been deeply reformed, cancelling by and large these two biases, but - for equity reasons - a smooth transition between the old and the new system has been implemented, and many workers probably speeded up even more their retirement decision in order not to loose the old system advantages. During the Eighties and the Nineties, moreover, in many occasions the policy maker faced the deep industrial restructurings that took place in those years by means of further early retirement provisions and long lasting unemployment benefits (the so called "mobilità lunga"). The effects on the average effective age of retirement are evident in Figure 3, drawn from Oecd [2004].

Moreover, if a pension holder decided to get back to dependent employment, its pension benefits were suspended. In case s/he decided to work as a self employed, a large allowance cut was carried out. This kind of arrangement resulted in a severe limitation of pension holders' labour offer, and in an incentive to be engaged in casual, black/grey work.

Figure 3. Average effective age of retirement by gender in Italy, 1960-2002

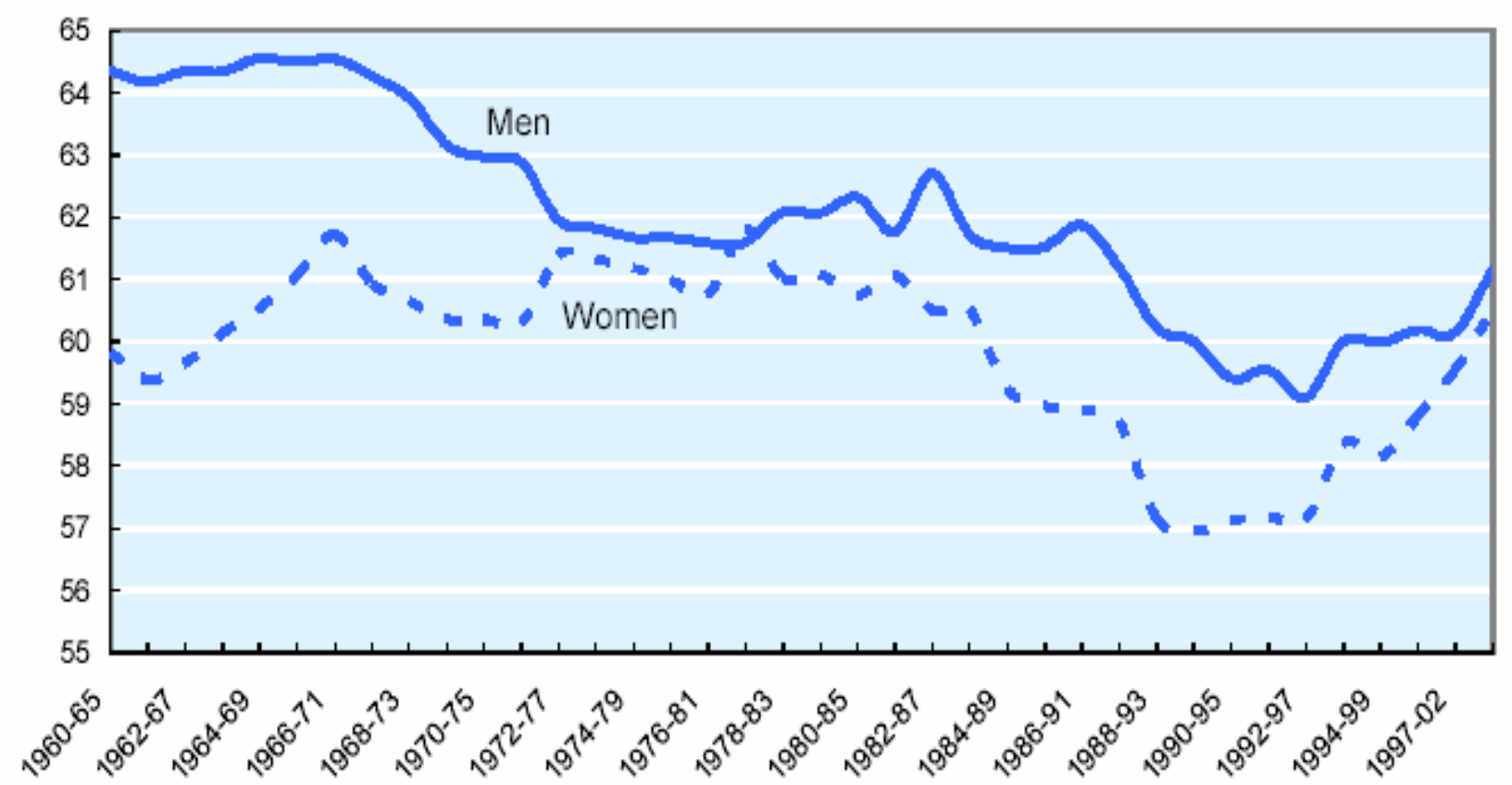

Source: Oecd (2004)

\section{Past choices, past events}

Taken together, the two selection processes have a large impact on participation profiles, and tend to smoothen international differences. In Figure 4 we plotted the employment rate for EU15 countries (but Luxembourg, for small sample issues) considering first all the elders, then those who had at least one working experience, and finally those who had a working experience and are not pension holders.

Italy is by and large the country were the cumulated effect is huger. As regards women both selection processes have a similar impact size, and the employment rate rises from $28 \%$ to $54 \%$ (from $13^{\text {th }}$ to $9^{\text {th }}$ in the rank). Among the other countries in which the participation of 
elder females is low, Greece and Belgium show a selection pattern similar to Italy's one. In Austria only the retirement effect is sizeable, while in Spain both effects are low. Also conditioning on having work experience, and not being pension holders, Spanish women in the 50-64 age group have employment rates as low as 30\%.

As regards men, the jump due to the retirement selection in Italy is the highest - slightly more than 26 percentage points. Conditioning on not being pension holders, Italy's employment rate ranks $6^{\text {th }}$ instead of $13^{\text {th }}$. In Austria and France the effect is sizeable too, hovering around 20 p.p. 
Figure 4. Employment rates of people aged 50-64, by gender and by selection events, 2000.

\section{females}

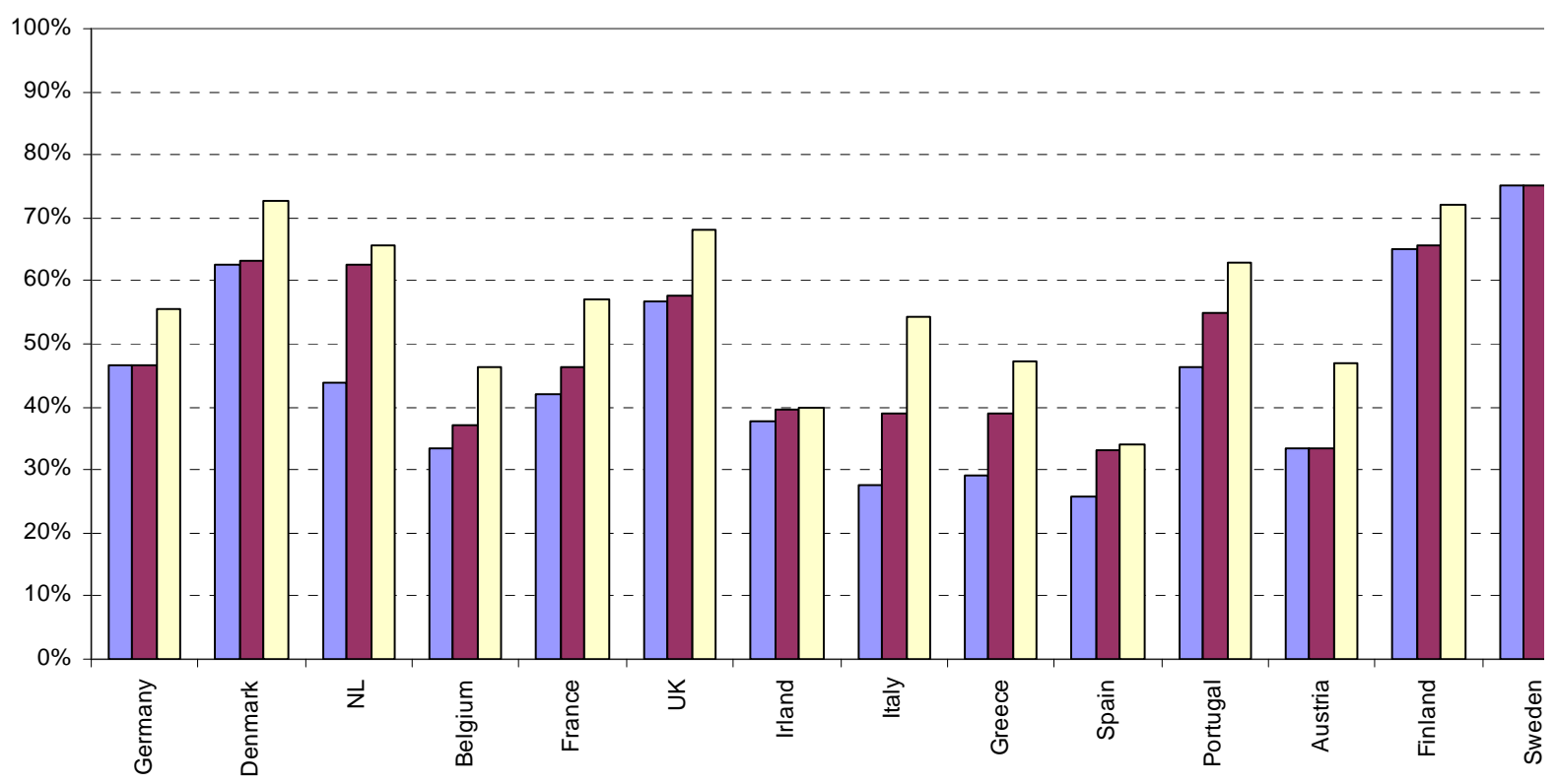

males

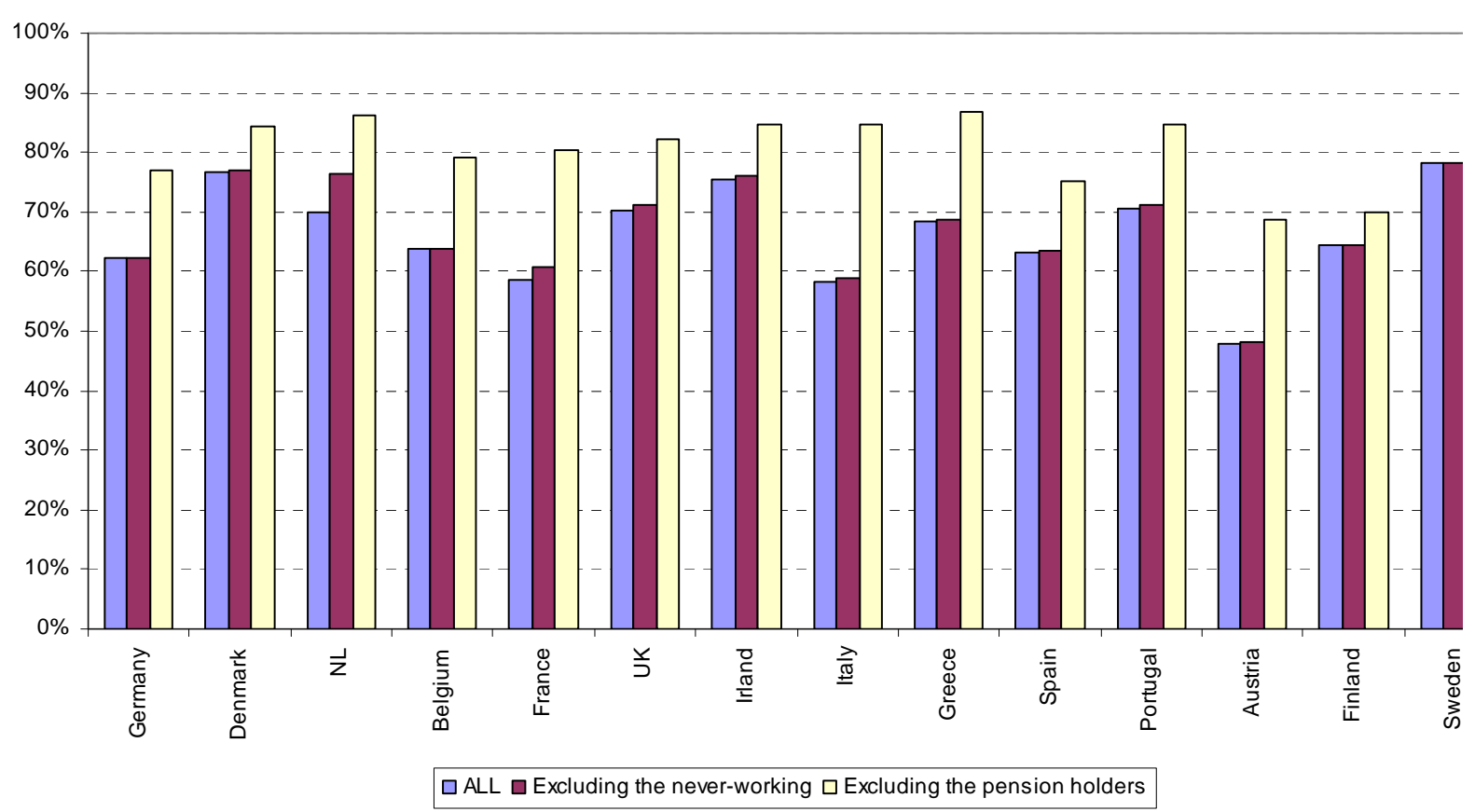

Source: Our elaborations on ECHP data, wave 7

\section{Conclusions and further research}

The differences in participation and employment rates of the elders are high across Europe. Some countries, like Sweden, Denmark and the United Kingdom, have figures that are largely in line with the targets that the European Commission set for 2010. In many member countries, on the contrary, they are worryingly low, particularly for what regards women. From a macroeconomic point of view this is a reason of concern because of the 
economic sustainability of an ageing society. From a microeconomic perspective, the issue at stake is whether in the labour market transitions that workers undergo during their working career there is a social risk to be managed. A low participation of a given target group can merely be a deliberate choice of the individuals. If this is the case the macro issue is the sole one. Yet, it can hide a sort of inactivity trap, and policies able to improve the employability of the individuals can be necessary.

Our aim has been to disentangle the different factors at work in shaping cross country differentials, to single out which are the most crucial areas to be further explored.

Cross sectional evidence signals that health status, the diffusion of part-time, and the educational attainment level are all positively correlated with elders' employment rate. Interestingly enough, however, when controlling for all individual characteristics the impact of education vanishes in many countries. It seems to be an important factor in enhancing the employability of the individuals only in those countries - like Italy and other SouthernMediterranean countries - where the elders on average tend to be less educated. There, higher education is somewhat a scarce resource in the elders labour supply. The issue, in these countries, is the very low participation rate of those with less than second stage educational level.

Family responsibilities are another key factor at work. In Italy, roughly one elder out of four looks after someone within the family, and the burden associated with this activity is rather high - comparable at least with a part time job in $70 \%$ of cases.

The most remarkable findings, however, came out adopting a life course perspective. We provided some evidence that there are two selection processes having a key role in explaining cross country differentials: the life cycle decision for women of not participating to the labour market, and the access to early retirement schemes.

Both are particularly important in explaining low participation rates in Italy. As regards women, for instance, if we exclude those who never worked, the employment rate in the 5064 age group increases by more than 10 percentage points (going from 27.6\% to 39\%). Considering only those who are not pension holders it further increases to $54.3 \%$. While the increase by itself has to be expected, its size is such that the gap from to the EU15 average falls down from 17 percentage points to just 4 p.p.

It has to be stressed that both selection processes can hardly be considered as random. Two major empirical issues are at stake. The first is to explore further the cross country differentials controlling for the mechanisms that generate the selection. Preliminary explorations on this area show that the selection equations tend to be significative in all countries. Hence, in multivariate analysis the selection process should be taken into account. The second is to try and ascertain whether there are barriers to late entries and re-entries in the labour market.

In order to derive sound policy conclusions from the findings we illustrated, some empirical evidence on the latter points is needed. Nonetheless, two policy implications can be put forth. The first is that barriers to late entries and re-entries in the labour market are sometimes present into the labour market regulations. We already cited the incompatibility between pension benefits and working activities. Another sensitive area is about minimum age requirements in personnel selection procedures.

The second is about a correct design of the target groups relevant to the issue of elders' low employment rates. One is composed by pensioners. In countries where early retirement schemes have been employed, a bulk of perfectly able workers have been filtered out of the market. They may be the target of a policy aimed at their re-employment, and/or their emersion from black/grey working activities. Although paradoxical, another relevant group are young and prime age women. We showed that the decision to offer their working effort within the household for child and family care can have long lasting consequences on their 
future participation behaviour. Policies aimed at achieving a greater compatibility between family care and working activities are to be considered a first step to ease the low participation issue in next decades. 


\section{References}

Auer P., Fortuny M. (2000) "Ageing of the Labour Force in OECD Countries: Economic and Social Consequences" ILO Employment paper 2000/2

Blondal S., Scarpetta S. (1998): "Retire Early, Stay at Work?", OECD Observer, No. 212, june-july

Blondal S., Scarpetta S. (1999): "Early Retirement in OECD Countries: The Role of Social Security Systems." In: OECD Economic Studies, No. 29

EUROSTAT, Labour Force Survey, various years

Gazier (ed) (1999), Employability: concepts and Policies, Report 1998, Employment Observatory Research network, European Commission, 329 p.

Marano A, Sestito P. (2004) "Older workers pensioners: the challenge of ageing of the italian public pension system and labour market" CERP working paper $n$. 32/04

Nicoletti C. and Peracchi F. (2001) "Ageing In Europe: What Can We Learn From The Europanel?" In T.Boeri, A.Börsch-Supan, A.Brugiavini, R.Disney, A.Kapteyn and F.Peracchi (eds.), Pensions: More Information, Less Ideology, Kluwer Academic Publishers, Netherlands.

OECD (2004), "Ageing and Employment Policies - Italy", Paris

Rhum C. J. (1989), "Why older Americans stop working”, The Gerontologist, Vol 29, Issue (3), p. 294-299. 


\section{Appendix}

\section{Table A1 Estimated logit models for the probability of being in the labour force - MEN}

(Robust standard errors. *** denotes an observed significance level below 1\%; ** denotes an observed significance level below 5\%, * denotes an observed significance level between $5 \%$ and $10 \%)$.

\begin{tabular}{|c|c|c|c|c|c|c|c|c|c|c|c|}
\hline Variable & Germany & Denmark & NL & Belgium & France & UK & Ireland & Italy & Greece & Spain & Portugal \\
\hline Intercept & 22.779 & $45.094 * * *$ & $24.930 * *$ & $32.077 \quad * * *$ & $29.155 * * *$ & $12.159 * *$ & 13.392 & $26.671 * * *$ & $30.473 \quad * * *$ & $30.225 \quad * * *$ & $13.272 * * *$ \\
\hline age & -0.308 & -0.358 & $-0.362 \quad * * *$ & -0.368 & $-0.463 \quad * * *$ & $-0.194 * * * *$ & $-0.188 \quad * * *$ & $-0.217 \quad * * *$ & -0.259 & $-0.268 \quad * * *$ & -0.157 \\
\hline high_edu & 0.547 & 0.072 & 0.250 & 0.595 & 0.658 & -0.149 & 0.681 & 1.327 & $-0.413 \quad * *$ & $0.466 \quad * *$ & 0.471 \\
\hline mid_edu & 0.234 & -0.068 & 0.207 & 0.497 & -0.100 & -0.011 & -0.046 & $0.369 \quad * * *$ & $-0.799 \quad * * *$ & -0.328 & -0.370 \\
\hline no_spouse & -0.277 & $-1.123 \quad * * *$ & $-0.528 * *$ & $-0.647 \quad * * *$ & $-0.279 *$ & $-0.471 \quad * * *$ & -0.330 & -0.025 & $-0.421 \quad *$ & $-0.490 \quad * * *$ & -0.268 \\
\hline child16 & 0.140 & -0.059 & $0.667 \quad * *$ & 0.174 & 0.393 & 0.014 & 0.278 & 0.337 & 0.172 & 0.013 & 0.071 \\
\hline good_health & 0.191 & 1.403 & 0.886 & 0.870 & 0.046 & 0.868 & 1.121 & 0.083 & 0.715 & 0.865 & 0.779 \\
\hline bad_health & $-0.851 \quad * * *$ & $-1.549 * * *$ & $-1.564 \quad * * *$ & -1.914 & $-1.493 \quad * * *$ & $-1.324 \quad * * *$ & $-2.184 \quad * * *$ & $-0.757 \quad * * *$ & $-1.604 \quad * * *$ & $-1.177 \quad * * *$ & $-1.270 \quad * * *$ \\
\hline income_eq & -2.256 & -6.570 & -2.227 & $-3.019 * * *$ & $-1.142 * * *$ & -1.263 & -1.143 & $-3.045 * * *$ & $-3.251 \quad * * *$ & $-3.397 \quad * * *$ & -0.282 \\
\hline income_eq2 & $0.192 \quad * * *$ & 0.432 & 0.185 & $0.192 \quad * * *$ & $0.093 \quad * * *$ & 0.125 & 0.102 & $0.169 \quad * * *$ & 0.182 & $0.206 \quad * * *$ & -0.006 \\
\hline lookaft_child & -0.648 & -0.551 & 0.240 & $-0.950 \quad * * *$ & $-0.915 \quad * * *$ & $-1.040 \quad * * *$ & $-0.633 \quad * * *$ & $-0.505 \quad * * *$ & -0.495 & $-1.255 \quad * * *$ & -0.401 \\
\hline lookaft_old & -0.090 & 0.009 & -0.200 & -0.068 & $-0.577 \quad * * *$ & $-0.605 \quad * * *$ & -0.664 & $-0.905 \quad * * *$ & -0.199 & -0.247 & 0.071 \\
\hline dyear1995 & -0.007 & -0.255 & . & -0.144 & $0.446 \quad * * *$ & 0.188 & -0.246 & $-0.160 \quad * * *$ & $-0.184 * *$ & $-0.260 \quad * * *$ & -0.024 \\
\hline dyear1996 & -0.190 & -0.337 & . & -0.091 & $0.542 \quad * * *$ & 0.148 & $-0.444 \quad * * *$ & $-0.122 *$ & $-0.230 \quad * * *$ & $-0.389 \quad * * *$ & -0.056 \\
\hline dyear1997 & -0.233 & $-0.634 \quad * * *$ & . & 0.069 & 0.117 & 0.216 & -0.264 & $-0.171 \quad * *$ & -0.191 & $-0.330 \quad * * *$ & -0.029 \\
\hline dyear1998 & -0.169 & -0.340 & . & $-0.271 *$ & 0.163 & 0.247 & $-0.302 *$ & $-0.310 \quad * * *$ & $-0.281 \quad * * *$ & $-0.294 \quad * * *$ & -0.155 \\
\hline dyear1999 & $-0.475 \quad * * *$ & $-0.460 *$ & 0.046 & -0.132 & -0.005 & 0.676 & $-0.417 \quad * *$ & $-0.372 * * *$ & $-0.454 \quad * * *$ & $-0.598 \quad * * *$ & -0.087 \\
\hline dyear2000 & $-0.678 \quad * * *$ & -0.386 & $0.265 \quad * *$ & -0.172 & 0.022 & 0.189 & $-0.382 *$ & $-0.296 \quad * * *$ & $-0.372 \quad * * *$ & $-0.602 \quad * * *$ & -0.080 \\
\hline N. obs & 9229 & 3402 & 2709 & 3445 & 7979 & 5507 & 5055 & 12105 & 8282 & 9639 & 7791 \\
\hline Somers' D & 0.730 & 0.803 & 0.780 & 0.762 & 0.818 & 0.648 & 0.650 & 0.557 & 0.641 & 0.669 & 0.520 \\
\hline Percent Concordant & 86.4 & 90.1 & 89.0 & 88.1 & 90.9 & 82.3 & 82.4 & 77.7 & 81.9 & 83.4 & 75.9 \\
\hline Percent Discordant & 13.4 & 9.8 & 10.9 & 11.8 & 9.0 & 17.5 & 17.4 & 22.1 & 17.9 & 16.5 & 23.9 \\
\hline Percent Tied & 0.1 & 0.1 & 0.1 & 0.1 & 0.1 & 0.2 & 0.2 & 0.2 & 0.2 & 0.2 & 0.3 \\
\hline
\end{tabular}




\section{Table A2 Estimated logit models for the probability of being in the labour force - WOMEN}

(Robust standard errors. *** denotes an observed significance level below 1\%; ** denotes an observed significance level below 5\%, * denotes an observed significance level between $5 \%$ and $10 \%$ ).

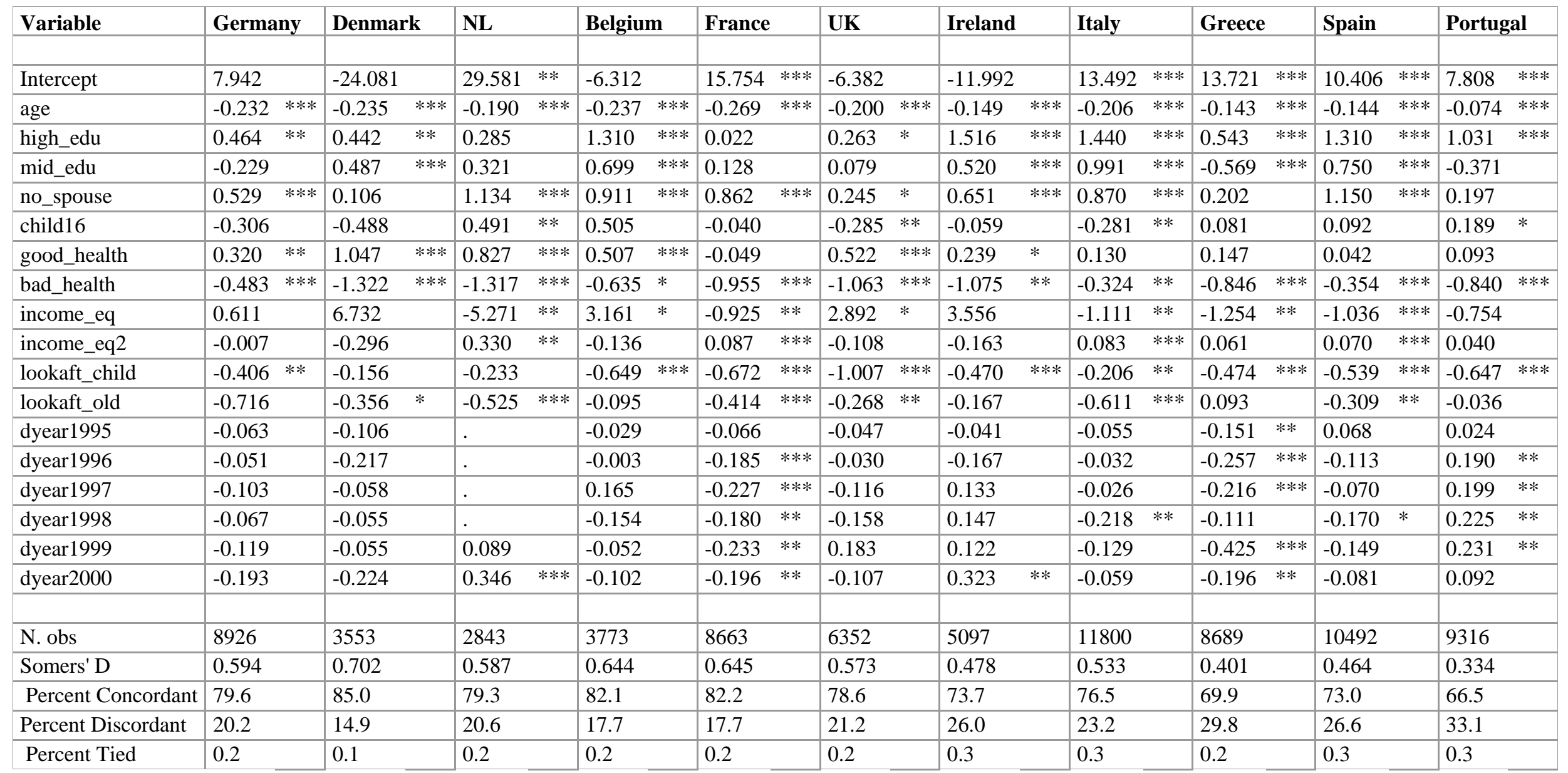

